\title{
CHARGE TRANSFER COMPLEX METHOD FOR THE ESTIMATION OF ETORICOXIB IN TABLETS
}

\author{
P.G.Sunitha*, N.Deattu, R. Ravi Kumar, S.Sri Rudhra, P.Kalaimathi, B. Soundiramani \\ College of Pharmacy, Madras Medical College, Chennai-600 003 \\ *Corresponding Author's E-mail id: sunitha.srm@gmail.com
}

\begin{abstract}
A simple and sensitive spectrophotometric method employing acid-dye technique was developed for the estimation of etoricoxib in pharmaceutical dosage form. The proposed method is based on the formation of ion-pair complex of etoricoxib with an acid dye, which is extracted into chloroform and the absorbance measured at the $\lambda_{\max }$ of the complex. The $\lambda_{\max }$ of the ion-pair complex was found to be $414 \mathrm{~nm}$. Beer's law was obeyed in the concentration range of $10-80 \mu \mathrm{g} / \mathrm{ml}$. The proposed method is statistically validated and found to be useful for the routine determination of etoricoxib in tablets.
\end{abstract}

Keywords: Etoricoxib, Spectrophotometry, Charge transfer complex, Tablets, Validation.

\section{INTRODUCTION:}

Etoricoxib (ETX) is a specific type of an antiinflammatory drug most commonly used for the relief of pain and swelling suffered by individuals ${ }^{1,2}$. Chemically it is 5-chloro-3-[4-methanesulfonyl phenyl]-2-[6-methyl pyridin-3-yl] pyridine ${ }^{3}$. Literature review revealed very few analytical methods including HPLC ${ }^{4}$, HPTLC 5 , LC$\mathrm{MS}^{6}$, Capillary zone electrophoresis ${ }^{7}$ and Ultraperformance liquid chromatography ${ }^{8}$ for simultaneous determination of etoricoxib in pharmaceutical dosage forms. In the present study spectrophotometric method employing acid-dye technique ${ }^{9}$ for determination of etoricoxib in pure form and tablets is described. The method is based on the formation of a charge transfer complex of the drug with an acid-dye, whose absorbance is measured at the $\lambda_{\max }$ of the complex, after extraction into chloroform.

\section{MATERIALS AND METHODS:}

\section{Instrumentation:}

All spectral and absorbance measurements were made on Shimadzu UV-VIS Spectrophotometer-1650.
Chloroform, bromothymolblue solution $(0.3 \% \mathrm{w} / \mathrm{v})$, buffer of different $\mathrm{pH}$ from 2.2 to 4.0 as per I.P.1996. All reagents used were of analytical grade.

\section{Preparation of standard solution:}

A $1 \mathrm{mg} / \mathrm{ml}$ stock solution of ETX was prepared by dissolving $100 \mathrm{mg}$ of drug in $100 \mathrm{ml}$ of ethanol.

\section{Procedure:}

Appropriate aliquots of the standard drug solution were pipetted out into a series of eight separating funnels. To each funnel $2 \mathrm{ml}$ of buffer and $5 \mathrm{ml}$ of dye solution were added and mixed thoroughly. The complex was extracted with three successive quantities each of $8 \mathrm{ml}$ of chloroform into $25 \mathrm{ml}$ volumetric flask and made upto volume with chloroform. The absorbance of the ion-pair complex was measured at the $\lambda_{\max }$ of the dye in the solvent against the reagent blank. The solutions were scanned in the spectrum mode in the wavelength range of $400-800 \mathrm{~nm}$. The $\lambda_{\max }$ of the complex was found to be $414 \mathrm{~nm}$ as shown in fig-1.The analytical curve was constructed by plotting concentration versus absorbance.

\section{Reagents:}

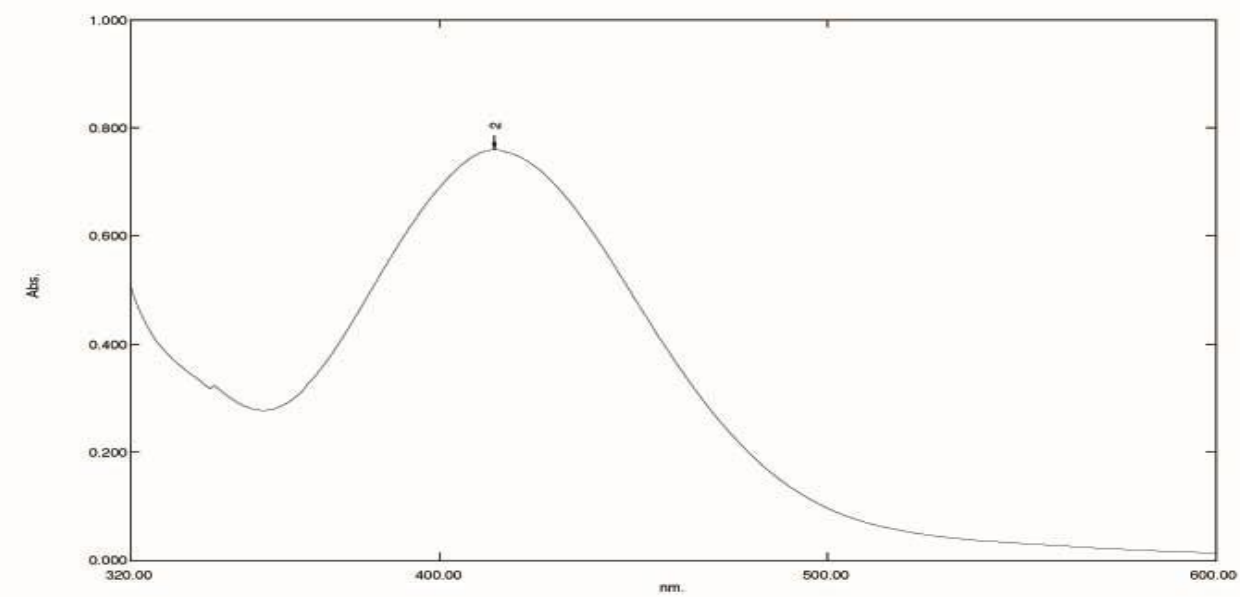

Figure 1: $\lambda_{\max }$ of the ion-pair complex of ETX 


\section{Sample Analysis:}

Twenty tablets were weighed and powdered. A quantity equivalent to about $100 \mathrm{mg}$ of etoricoxib was weighed accurately, transferred to a beaker, disssolved in ethanol, filtered through Whatmann filter paper No.1 into $100 \mathrm{ml}$ volumetric flask and made upto volume with ethanol. Appropriate aliquots (within Beer's law concentration ) were subjected to the above procedure and the amount of etoricoxib was determined from the calibration curve. The results are furnished in Table- 2.

\section{RESULTS AND DISCUSSION:}

Etoricoxib was found to yield a coloured product with the dye bromothymolblue due to the formation of an ion-pair complex. The $\lambda_{\max }$ of the etoricoxib complex with bromothymol blue was found to be $414 \mathrm{~nm}$. The optimum
$\mathrm{pH}$ for the formation of complex was found to be 2.2. The optical characteristics such as absorption maxima, Beer's law limits, molar absorptivity and Sandell's sensitivity are furnished in Table-1. The regression characteristics like slope $(m)$, intercept(c), correlation co-efficient(r), percent relative standard deviation(\% RSD) and standard error(SE) were calculated and the results are summarized in Table-1. The amount of drug determined was in good agreement with the label claim showing the accuracy of the proposed method. To study the accuracy and reproducibility of the proposed method, recovery experiments were carried out by adding a known amount of drug to preanalysed sample and the percentage recovery was calculated. The percentage of recovery was around $100 \%$ proving the reproducibility of the method. The results are furnished in Table-2. The results indicate that there is no interference of other ingredients present in the formulations.

Table 1: Optical and Statistical Parameters

\begin{tabular}{|l|l|}
\hline Parameters & Results \\
\hline$\lambda_{\max }(\mathrm{nm})$ & 414 \\
\hline Beer's law limits $(\mu \mathrm{g} / \mathrm{ml})$ & $10-80$ \\
\hline Molar absorptivity $\left(\mathrm{L} \mathrm{mol}^{-1} \mathrm{~cm}^{-1}\right)$ & 359.35 \\
\hline Sandell's senstivity $\left(\mu \mathrm{g} / \mathrm{cm}^{2} / 0.001\right.$ absorbance unit $)$ & 0.00892 \\
\hline Regression equation $(* \mathrm{y})$ & $0.0111 \mathrm{x}+0.0019$ \\
\hline Slope $(\mathrm{m})$ & 0.0111 \\
\hline Intercept $(\mathrm{c})$ & 0.0019 \\
\hline Correlation co-efficient $(\mathrm{r})$ & 0.9998 \\
\hline \%RSD & 0.005382 \\
\hline Standard error(SE) $\quad 0.1141$ \\
\hline
\end{tabular}

Table 2: Assay and recovery of ETX in dosage form

\begin{tabular}{|c|c|c|c|}
\hline Drug & Labelled amount (mg) & Amount obtained (mg)* & Percentage recovery* \\
\hline Etoricoxib & 60 & 60.005 & 100.03 \\
\hline
\end{tabular}

\section{CONCLUSION:}

The proposed method is simple,economical,sensitive,accurate,reproducible and useful for the routine determination of etoricoxib in tablets.

\section{ACKNOWLEDGEMENTS:}

We are thankful to the Department of Pharmaceutical Chemistry, Madras Medical College,Chennai-03, for providing the instrumentation and laboratory facilities.

\section{REFERENCES:}

1. Tripati KD, Essentials of Medical Pharmacology, $\mathbf{6}^{\text {th }}$ Edition, Jaypee brothers Medical Publishers 2006. P.187,198.

2. Moroes BM, Amaral BC, Morimoto MS, Vieira LG, Perazo FF, Carvalho JC. Anti-inflammatory and analgesics actions of Etoricoxib(an NSAID) combined with misprostol. Inflammo Phamacology 2007;15:175-8.

3. Martindale, The complete drug reference, $3^{\text {rd }}$ Edition, VolI.P.46.

4. Patel HM, Suhagia BN, Shah SA, Rathod IS. Determination of Etoricoxib in pharmaceutical formulations by HPLC method. Indian J Pharma Sci 2007;67:703-5.

5. Baheti KG, Shaikh S, Shah N, Dehghan MH. Validated simultaneously estimation of Etoricoxib in bulk and tablet by HPTLC method. Inter J Res Pharma Biomed Sci 2011;2:672-75.
6. Brum L Jr, Fronza M, Ceni DC, Barth T, Dalmora SL. Validation of liquid hromatogaaphy and liquid chromatography/tandem mass spectrometry methods for the determination of Etoricoxib in pharmaceutical formulations. JA OAC Int 2006;89:1268-75.

7. Dalmora SL, Shangoi Mda S, da Silva LM, Macedo RO, Barth T. Validation of a capillary zone electrophoresis method for the comparative determination of Etoricoxib in pharmaceutical formulations. J Sep Sci 2008;31:169-76.

8. Vora DN, Kadav AA, Separation of Etoricoxib and its degradation products in drug substance using UPLC TM. Eurasian J Ana Chem 2007; 2:182-9.

9. Beckett.A.H, Stenlake J.B, Practical Pharmaceutical Chemistry, Vol.II, $4^{\text {th }}$ edition, CBS Publishers, 1997.P.304. 